\title{
Water Resources Development in Nepal: Myths and Realities
}

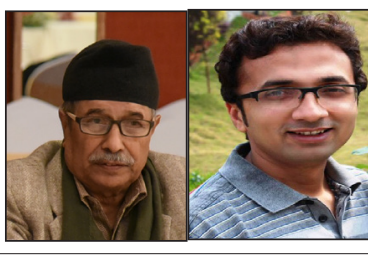

Surya Nath Upadhyay and Prakash Gaudel

Surya Nath Upadhyay Prakash Gaude

Abstract: Despite the 'immense' water resources available, Nepal has not been able to transform this abundance of water resources into desired economic growth and societal welfare. This paper attempts to analyze the reasons for such incessant challenges that loom over water resources development in Nepal. This paper finds that it is not the resource that limits the development of water resources, but the approaches and wishes that are framed on the foundation of persistent myths. Analyzing those myths, this paper highlights the realities in water resources management of $\mathrm{Nepal}$, and suggests that without dismantling the existing myths, the sustainable development of water resources seems limited.

Keywords: Water resources, hydroelectricity, cooperation, downstream benefit sharing, Nepal

\section{Background}

Droper management of water resources is a key to desired socio-economic growth. For a country like Nepal, where the Monsoon brings much of the rainfall, it is not the water itself that limit the development, rather it is the lack of governance and management. As a result, Nepal has not been able to achieve the anticipated growth and development. Attempts have been made in the past, to harness the water resources; however, the development is not achieved as expected. It is high time for Nepal to rectify the mistakes of the past and pave the road to new era of sustainable water management. For this, it is necessary to first look into the mistakes of the past. This paper attempts to identify and analyze the myths that have influenced the policies related to water resources management in Nepal that have resulted in some 'uncomfortable' realities.

\section{Myth 1: Nepal is Rich in Water Resources}

Nepal is considered rich in terms of water resources. The surface water availability in Nepal is estimated to be about 225 billion cubic meters (BCM) per annum which is equivalent to an average flow of $7125 \mathrm{~m}^{3} / \mathrm{s}$ (WECS, 2005). This availability is contributed by the annual precipitation, both in the form of rain and snow. About $10 \%$ of the total precipitation in Nepal falls as snow and $23 \%$ of total area lies above $5000 m$ in permanent snowline in Nepal (MoPE, 2004). Further, 3.6\% of Nepal's total area is covered by glaciers (WECS, 2011).

These figures above depict that the availability of water resources in Nepal is quite impressive. However, there is a less discussed another side to it. The diverse geography and topography creates spatial and temporal variations in precipitation across Nepal. About $80 \%$ of the annual rainfall occurs as monsoon in four months; June to September only. Even in large perennial rivers, the dry season flow on an average year is only $12.5 \%$ of the annual flow (WECS, 2002). This implies that floods during monsoon contain much of the annual river flow creating temporal variation in water availability. In more specific terms, the volume of monsoon flow to the total annual runoff is between 73 to $75 \%$ for large rivers and $83 \%$ for medium-sized rivers (Bhattarai, 2009). Due to such temporal variation in water availability, the medium-sized rivers basins like Kankai, Bagmati and Babai are referred to as 'deficit' basins whereas the large rivers; Koshi, Gandaki, Karnali and Mahakali are referred to as 'surplus' basins (WECS, 2002). In contrast to the low water availability in dry season, there is high demand of water for consumptive use and nonconsumptive use for hydroelectric power generation. The situation is further aggravated by the fact that much of the Nepalese population lives in water deficit basins ${ }^{2}$. Thus the locations where water can be used, do not always coincide with the locations where water is easily available (WECS, 2002). Therefore, unless the water resources are managed efficiently, water scarcity will remain persistent in Nepal.

Water plays a pivotal role in maintaining food and energy security. Efficient management of water can increase food production and provide reliable and clean energy. Despite the abundant water resources available, Nepal has not been able to achieve self-sustenance in food and energy supply and, thus, depends mainly on imports. Out of the total $225 \mathrm{BCM}$ annually available surface water, only $15 \mathrm{BCM}$ is in use (WECS, 2005). Around $95.9 \%$ of this 15 BCM is being used for agriculture, $3.8 \%$ for domestic purpose and only about $0.3 \%$ for industrial purpose (WECS, 2011). Per capita water consumption is far below of per capita water availability but still $16.4 \%$ of the Nepalese household lack access to basic drinking water (NPC, 2016; MoF, 2016). Though Nepal has 1.76 million hectares of irrigable agricultural land, less than one-third of it has year round irrigation facilities (WECS, 2005). Similarly, per capita electricity consumption of Nepal is one of the lowest in South Asian region. Thus, the poor water resources development and management has resulted in poor socio-economic development of the country and the popular saying 'Nepal is rich in water 
resources' has remained a myth.

\section{Myth 2: Nepal can Get Rich by Selling Hydroelectricity}

The perennial rivers with high gradient make Nepal an ideal place for hydroelectricity generation. The estimated hydropower potential of Nepal is 83,000 $\mathrm{MW}^{3}$. A recent study (WECS, 2017) has identified 114 projects with total capacity of 45,610 MW as technically feasible and only 66 projects with total capacity of 42,133 MW as economically feasible.

Even though Nepal is endowed with such large techno-economically feasible hydropower potential, the current generation is only around $1000 \mathrm{MW}^{4}$. With this installed capacity, Nepal is not able to fulfill the internal demand of electricity and depends on import from India, particularly in the dry season. However, the hydropower development related policies assume that hydroelectricity may be exported to India and beyond. Unfortunately, this wrong assumption has crept into the mind of the planner because of the possibility across the border and we have been negotiating on cooperation with India on water resources development for decades. There have been talks of energy cooperation in South Asia and the SAARC ${ }^{5}$ energy grid has been in the offing for quite some time. Besides, there has been a steady emphasis on foreign investment in Nepal and hydropower is one of the various sectors. As such, task forces were formed to advise the government to prepare plans which can ameliorate the energy crunch in the country and could also sell energy across the borders and beyond. The taskforce for formulating the 10-year Hydroelectricity Development Plan in 2009 prescribed the generation of $10,000 \mathrm{MW}$ in ten years. This 10 year plan envisages the development of storage and non-storage projects in the ratio of 60:40, so that Nepal can export 3,000 to 5,000 MW of electricity. Whereas the next task force formed in 2011 came up with the figures of 25,000 MW in 20 years. Since the generated electricity cannot fully be consumed in Nepal, the task force recommends for export to India.

Moving from 2009 to 2011 and till date, no substantial progress has been made in the hydropower sector. Instead of analyzing the success or failure of these plans prepared by the task forces, the Ministry of Energy has again come up with another plan of 10,000 MW in 10year Electricity Development Decade ${ }^{6}$ from 2016 to 2026. Pun (2017) has entailed this theme of generating 10,000 MW in this decade, which has now been upgraded to $17,000 \mathrm{MW}$ in 7 years, as a new toy of Ministry of Energy.

So, in just 7 years of time, we have three big plans aimed at making radical changes in hydropower production and possibly export as well. However, no generous progress has been made and we are still importing electricity. Such unplanned and 'fancy' plans, prepared one after another, without any stake-taking and ownership by the concerned line agencies has kept the whole hydropower sector in an impasse. There are three serious issues in such plans.

Firstly, as the hydropower related policies are, regrettably, focusing on large scale projects; there is less attention given towards small and medium sized projects that are best suited for fulfilling domestic demands. The priority focus is on large scale projects which require utilizing external resources in terms of technical expertise and large investments may thwart the gradual learning process in the country.

Secondly, the world has already noticed that selling hydroelectricity would not necessarily lead to prosperity. Inferences can be drawn from other hydro-rich but economically weak nations who have sold electricity but not been able to improve their conditions. Paraguay's hydroelectricity export is one of the typical examples where Paraguay alone is the main electricity exporter in South America but is still the second poorest nation in the region (Pun, 2008b; Thanju and Canese, 2011). Similarly, the ever cited example for Nepal is the Bhutanese Model of hydroelectricity generation. But despite the export of hydroelectricity to India at nominal rates $^{7}$, Bhutan needs to import the electricity back from India in dry season and thus the Bhutanese Model is not a panacea. Therefore, the use of hydroelectricity, as renewable and sustainable source of energy for fulfilling internal consumption demands, to achieve desired economic growth rather than just exporting as a raw material should be the primary goal. This policy should not, however, totally negate the possibility of exporting energy where possible. In fact, a connected grid between two or more than two countries may envisage a power trading among them and in many cases this is just the normal way of power development in a free and nondiscriminatory trading regime in energy. However, this could not move forward in our region and hence power trading remains a myth; proving to be a case of running after a mirage.

Thirdly, the regional market for the electricity in South Asia is not as easy as depicted in national policies. Recently, India's Guidelines on Cross Border Trade of Electricity, 2016 has clearly shown that the dream of getting rich by selling hydroelectricity to India is not an easy $\operatorname{task}^{8}$. Nevertheless, the perception of the Nepalese policy makers to see India as the only market in the region is prevalent. But what is constantly being ignored is that for India, electricity trade is of strategic importance as reflected in the Guidelines. Since India's installed capacity is over $300,000 \mathrm{MW}^{9}$ and has been moving on with around 100,000 MW every five year; there is little significance of Nepal's (to be exported) hydropower in the Indian electricity market. Moreover, the Indian approach towards cooperation with Nepal on water resources is mainly focused with the intention of 
getting water rather than energy from the rivers of Nepal.

So, these three pertinent issues clearly depict that the economic growth at the cost of hydroelectricity sale is, so far, only a myth for Nepal. Despite hydroelectricity sales being a myth, it is constantly and repeatedly being reflected not only in national policies but also equally by multilateral agencies. The World Bank's Ganges Strategic Basin Assessment Report (2014) has emphasized that dams in the upstream region-Nepal would provide hydropower as the greatest benefits and there is little to do with flood control and water regulation in the downstream. The report has further highlighted that the potential for power trade among the basin countries is significant and simple to negotiate. With such inferences, the report attempted to strengthen two myths. First, the benefits are to be reaped by hydropower export through easy negotiations. Second, the downstream benefits of flood control and dry season flow augmentation are very limited. Pun (2013) strongly portrayed the report as Indo-centric and suggested Nepal not to rush just because of significant power trade. This report was heavily criticized and ignored by the experts of Nepal and even the government bodies simply did not take it into attention.

\section{Myth 3: Downstream Benefit Sharing Principle works for Ganges Basin}

The downstream benefit sharing principle has been adopted notably in management of some international water courses around the world. So, the principle of sharing the downstream benefits on international water courses is equally recognized as principle of international law. However, in the case of Ganges basin which encompasses China, Nepal, India and Bangladesh; this principle has not yet been acknowledged. Though many bilateral treaties and agreements have been signed between these riparian countries; the multilateral approach on Ganges basin management has yet not succeeded.

Among the four riparian countries of the Ganges, Nepal and India have signed three major bilateral agreements (Kosi-1954, Gandak-1959 and Mahakali-1996) related to development of transboundary rivers. Despite improving the water cooperation, controversies over the existing bilateral treaties have made transboundary water management a contentious issue between Nepal and India. And to date, no meaningful harnessing of the vast water resources available to both countries has materialized (Upadhyay and Gaudel, 2014).

Unlike the Kosi and Gandak Agreements which were done in 1950s, the Mahakali Treaty was based on the equitable utilization of water resources between Nepal and India. One of the important aspects of the Treaty was to conceive jointly the implementation of Pancheshwor Multipurpose Project based on the cost and benefits that incur to each country. The percentage of the cost to be invested by each country was to be determined by the relative benefits that each country would receive. With such provisions, the Treaty has implicitly adopted the downstream benefit sharing principle. However, even after two decades of signing the Mahakali Treaty, virtually nothing has been materialized. Because of India's intransigent behavior regarding the interpretation and implementation of the Treaty's otherwise clear provisions, the Treaty went through rough conditions. And again the Treaty resulted in India reaping heavily one-sided benefits, and left the Pancheshwar Project in the lurch (Upadhyay and Gaudel, 2014). Therefore, downstream benefit sharing has remained a myth.

The large multipurpose storage projects like Pancheshwor have broad implications on economy and will encounter social, technical, environmental and legal problems which are practically insurmountable to deal in isolation. Therefore, it is not advisable for Nepal to conceive and implement any such project in isolation (WECS, 2002; Poudel, 2009). Such projects with regional implications including the downstream benefits require regional cooperation among the riparian countries, and unless such cooperation is attained, Nepal should refrain from such mega projects and focus on fulfilling own needs through small and medium sized projects. Ironically, policy makers of Nepal are also responsible for maintaining downstream benefit sharing principle as a myth to a larger extent. This is because they are primarily driven by the myth of getting rich by selling hydroelectricity, disregarding multiple benefits of storing water and thus reluctant towards establishing downstream benefit sharing between riparian countries. Though such downstream benefit sharing has become myth for Nepal, India on the other side is sitting silent as the downstream benefits are to be received by default due to upstream water storage projects initiated by Nepal. One can take the example of Budhi Gandaki Storage Project (1200 MW). Nepal is solely building this project on Budhi Gandaki River which is a tributary of transboundary Gandak River. There has not been any talks with India. There is a possibility of releasing extra water during dry season and attenuating the water during the monsoon period which would create flood control benefits downstream including India. However, no any effort seems toward internalizing these multiple aspects of the project. Perhaps it is ignored mainly because of the fear that if entangled in the bilateral discussions the project would be delayed and the muchneeded energy to Nepal would not be available. This kind of distrust between the two countries mainly due to the past behavior has really been a stumbling block for embarking on projects for mutual benefit of the two countries. 


\section{Myth 4: Multilateral Cooperation exists in Ganges Basin}

The discussion on multilateral cooperation in the region started in 1980s, more precisely with the formation of South Asian Association for Regional Cooperation (SAARC). This was also the time when the dispute over the Ganges between Bangladesh and India was on rise regarding the construction of the Farakka barrage in India. The dispute was mainly on waters of lean season. As a resolution to the increasing water demand and reducing water flows in the basin, Bangladesh proposed for construction of high dams in upstream region of the Ganges Basin through multilateral cooperation. Though Nepal is the main contributor of the bulk of water in the dry season, India deliberately refrained Nepal from the negotiation of utilizing Ganges water (Upadhyay, 2012). Nevertheless, Nepal has emphasized the need for regional-cooperation in water resources in some of the early SAARC summits. However, since the inception of cooperation in Dhaka Summit of 1985, nothing has been achieved mainly due to disagreement of India (Upadhyay, 2012).

India has always treated Ganges as an Indian River and has been dealing separately, on bilateral basis, with the upper riparian Nepal and lower riparian Bangladesh. The water policy of India towards its neighboring riparian countries has always been to 'act first' and 'then only negotiate' if necessary. Such events of acting first without informing riparian countries have already been observed in the past ${ }^{10}$. Hence, in the context where India is in the dominant position in SAARC and so in the Ganges basin, there is literally no hope that anything of regional or multilateral substance can happen. Therefore, the multilateral cooperation which was foreseen as a muchneeded approach in the Ganges basin for the sustainable development of all associated countries and people, has remained persistently as a myth. It is a pity to observe that water resource is not anywhere in the list of areas of cooperation, which have been identified so far by SAARC (Upadhyay, 2012).

\section{Uncomfortable Realities}

The existence of these myths has been propelled by the physical situation of the riparian countries of the Ganges Basin. Had these countries come together and manage the water and energy within the Ganges Basin, much could have been done for the benefits of the people of these countries. Unfortunately, the political economy of these countries has over ridden the physical possibilities. And as such the realities have turned into the myths. Such situation has contributed to the poor water resources development within Nepal. These myths have been so persistent and have fragmented and weakened the institutions. In addition, multiple institutions with overlapping scope have been created resulting in ambiguity, confusion and conflicts. Some major realities, which are harsh as well as uncomfortable, in the policy and institutional framework related to water resources are discussed in the following subsections.

\section{Reality 1: Fragmented Institutions}

The Integrated Water Resource Management (IWRM) principles call for holistic and integrated approach for development of water resources. This requires coordination among all the waters use sectors and institutions and, thus, calls for an apex body which can coordinate and make decisions from the basin wide perspective. With that objective, the IWRM principles were first adopted in Nepal through Water Resources Strategy (WRS), 2002. However, much before this adoption, Nepal had already established an apex body 'The Ministry of Water Resources' (MoWR) in 1980.

It was in 2009, just after seven years of formulation of WRS, the MoWR was fragmented into Ministry of Energy and Ministry of Irrigation. This decision not only lead to the loss of institutional memory but also confined the water resources as two sectoral uses of hydropower and irrigation. In absence of apex body, the whole water resources sector has suffered and the future of waterbased development remains at crossroads. However, with the promulgation of new Constitution, the ministry has been restored recently in 2018 as the Ministry of Energy, Water Resources and Irrigation.

\section{Reality 2: Weakened Institutions}

The Water and Energy Commission Secretariat (WECS) has been envisioned as the designated and empowered government body to coordinate national level planning for the water sector by WRS, 2002. Similarly, in order to promote effective regional (and bilateral) cooperation, WRS, 2002 has further envisaged the establishment of Nepal International River Commission. However, no progress has been made in this direction which has resulted in the deterioration of faith regarding the negotiations on sharing of water and water related benefits. This is because WECS has been weakened and just used as a dumping ground of technical bureaucrats (Pun, 2016).

\section{Reality 3: Multiple Institutions with Overlapping Scope}

In the absence of apex body- MoWR for last eight years, multiple institutions related to water resources use have been established which have overlapping scope. This is particularly significant in the case of hydropower sector. After the formation of Energy Ministry in 2009 by scissoring of MoWR, the focus has only been kept on hydroelectricity. Even though, the energy security of the country is still in a limbo. This is mainly attributed to the creation of multiple institutions with overlapping scope resulting in lack of coordination and duplication of works. For instance, with the objective of facilitating economic development of Nepal by creating an investment-friendly environment, Investment Board 
Nepal (IBN) was established in 2011, two years after fragmentation of MoWR. As IBN has been mandated with scope of implementing hydroelectric projects with capacity of $500 \mathrm{MW}$ or more, there have been repeated tensions and conflicts between IBN and Energy Ministry.

More recently, the Energy Ministry has established two government companies- National Transmission Grid Company in 2015 and Electricity Generation Company in 2016. These two companies are parallel institutions to the already existing Nepal Electricity Authority $(\mathrm{NEA})^{11}$, which is mandated for generation, transmission and distribution of electricity. More specifically, NEA has its own separate directorates for transmission and generation which contradict with the mandate of newly established Energy Ministry's companies. This situation may be corrected by addressing the issues relating to energy development in the country and its regulation and trading. In fact, institutions are being partially created based on a future vision of energy development in the country. In the absence of concomitant development, the institutions have become lame ducks.

Similarly, Department of Electricity Development (DoED), under Energy Ministry which was working as a regulatory body for hydropower sector by providing 'one window service' and license to power project, has now been mandated with developing the hydropower project by own. This has further created the overlapping scope with the already existing hydropower producersthe government owned NEA and Independent Power Producers (IPPs). Moreover, with mandate to DoED to implement $20 \mathrm{MW}$ Budhi Ganga as its first project, Pun (2016) clearly indicates that DoED would much rather execute projects than be engaged in updating master plans for generation, transmission or distribution.

\section{Reality 4: Isolated Planning/Decision Making}

Most often, in recent years, planning and decisions regarding use of water resources were done in isolation, focusing on single use. Due to different scope provided to different institutions and in the absence of apex body-the MoWR, it may be seemed as obvious to have sectoral and isolated decisions. For instance, the Project Development Agreement (PDA) carried out through IBN for the development of 900 MW Upper Karnali hydropower project had no coordination with the Irrigation Ministry which was developing the RaniJamara-Kularia Irrigation project downstream of the hydropower project.

\section{Reality 5: Myopic Visions}

After the formation of MoWR in 1980, water resources development master plans were prepared for major basins of Nepal. Though such basin approach was realized much before the adoption of IWRM principles, with the fragmentation of MoWR, the decisions on water resources development have been mainly influenced by myopic visions. For instance, Tamor storage project was identified as a promising project by the Kosi Basin Master Plan (MoWR, 1985). However, this project is now in a limbo as DoED has already issued generation license, without taking into account the master plan, to private hydro-developers to execute projects ${ }^{12}$ in the reservoir area of Tamor project. Because of these already issued licenses, the department is reluctant to issues license for $762 \mathrm{MW}^{13}$ Tamor storage project.

In addition to such reluctance to basin level study and master plans, there has not been any priority selection of the projects. The Electricity Act, 1992 and the Water Resources Act, 1992 have over time, become obsolete. The Electricity Act has authorized the government to issue license for hydropower development on the basis of first come first service. It does not base the issuance of license on the basis of hydropower master plan; which has resulted in the failure of the priority selection of the project at present and for the future. Similarly, there is no plan till date to use the regulated water and other multiple benefits from the 'nation's pride' 1200 MW Budhi Gandaki Storage Project which is only being promoted as a hydropower project. Same is the case with the Energy Ministry's 'Electricity Development Decade' which has failed to see and realize Nepal's position in Ganges basin regarding the storage hydropower projects. The disintegration of MoWR, to a larger extent, is attributed for the failure to see the larger Ganges picture while framing hydropower plans and policies (Pun, 2017). Such myopic visions and nasty decisions will have long term implications on optimal utilization and management of available water resources.

\section{Silver Lining in the Water Sector}

Even though the above mentioned realities are harsh and uncomfortable, what really helped in meeting the national need of energy is the emergence of the private investors in the hydropower sector. What came out of the Electricity Act, 1992 with the adoption of the principles of globalization and liberalization in hydropower sector are two different upshots. The major upshot was the involvement of multilateral private agencies and 'Dollared' power purchase agreements (PPAs). Such 'Dollared' PPAs, mainly of Khimti (6o MW) and Bhotekoshi (36 MW) hydroelectric projects (HEPs) were litmus test for liberalized hydropower of Nepal. On the contrary, another important upshot was the successful implementation of small and medium sized hydroelectric projects by the Nepalese developers. Pun (2008a) has explained this as the Silver Lining of the Hydropower Development Policy, 2001. The Nepalese people are now the shareholders of many hydroelectric projects and half of the royalty generated from these projects return back to local levels. These are some key steps towards sustainable development of hydropower, irrespective of persistent myths and uncomfortable realities. 
Regardless of such an encouraging startup by the Nepalese developers, Nepal has its main focus on larger projects with 'foreign investors'. This has been reflected by the formation of IBN who has been mandate to secure funds for the hydro-projects with capacity of more than 500 MW. This has resulted in completion of project development agreements (PDAs) of two hydroelectric projects- Upper Karnali and Arun III HEPs, each 900 MW, with two Indian companies. Unfortunately, what is consistently being overlooked is the domestic capacity of hydro-developers. If the Nepalese internal resources can develop 456 MW Upper Tamakoshi HEP, why do we still have to look for foreign investment? If 22 MW Chilime HEP project can start $250 \mathrm{MW}$ projects, what is the next project of Upper Tamakoshi project?

In the case of irrigation sector, one notable step has been taken irrespective of all myths and uncomfortable realities. With the main objective of providing irrigation facility within Nepal, Bheri-Babai diversion project was initiated in 2015. This diversion project is a multipurpose project which envisages the diversion of $40 \mathrm{~m}^{3} / \mathrm{s}$ of water from 'water surplus' Bheri River to 'water deficit' Babai River. The project upon completion will provide year-round irrigation to 51,00o ha of agricultural land in Banke and Bardiya districts and generate $48 \mathrm{MW}$ of hydroelectricity. Projects like Bheri-Babai are much needed for Nepal which will serve the dual purpose of fulfilling the domestic and irrigation demands.

\section{Policy Intervention}

The overall development of the nation needs to be based on the foundation of water resources development and its sustainable management. This can be achieved through sustainable development of different sectors of water which include domestic water supply, irrigation, industrial water supply, hydropower, flood control, navigation, fisheries and environment. For achieving such sectoral development, planning needs to be done in an integrated manner; not in isolation. In the context of new federal structure of Nepal, attempts should be made to internalize the integrated development of water resources which was already been envisaged by the WRS, 2002.

The primary focus of the Nepal's policies need to be on those water resource projects, in particular hydropower, for fulfilling internal demand. Hydroelectricity development may require export and import of energy with India. An interconnected grid and power trading is taking shape between Nepal and India. This is a good sign. However, it again depends upon India to institute a non-discriminatory and open access regime on electricity trading between the two countries. Unfortunately, the recent developments, particularly the issuance of the directives by the Indian government throws cold water to such bright prospect. Regarding multilateral cooperation, Nepal has yet to see the practice of international law which has acknowledged the principle of downstream benefit as well as the safeguard of rights of the riparian who are late comers in use of international water course (Upadhyay and Gaudel, 2017).

\section{Conclusion and Way Forward}

What we have learned from the past institutional models and decisions on water resources management are crucial in framing the future paths. In context of new federal structures amalgamated with the increasing demand, reducing supplies and changing climate, decision making on water resources will provoke long term impacts on the overall development of the nation. It is therefore, high time for Nepal to dismantle the existing myths and improve the uncomfortable realities. Careful scrutiny is required for selecting such projects so that there is no conflict with the scope of potentially identified larger storage projects as in the case of Tamor HEP. It is also essential to realize that the electricity sale should not be overemphasized; rather the electricity should be used within the country to enhance prosperity. Increasing per capita electricity consumptions would help to achieve the desired socio-economic growth. In the case of export oriented large storage projects, there is a need of high level trust to be developed between nations and settlement of issues related to augmented flows and benefit sharing.

With the new Constitution being promulgated in Nepal, the restoration of the apex body as Ministry of Energy, Water Resources and Irrigation is being mulled over, which is to be taken as a silver lining in the water resources sector. From this analysis, it can be expected that with the learning from the past, Nepal will pave the path towards sustainable utilization and management of its abundant water resources leading to desired socioeconomic growth and development.

Surya Nath Upadhyay, LLM, from London University served the Government of Nepal for more than three decades and held various important and critical positions such as Secretary, Ministry of Water Resources; Chief Commissioner of the Commission for the Investigation of Abuse of Authority etc. During his career of civil servant, he remained involved in water resources for many years and preformed various roles - adviser, negotiator and decision maker. He has published several reports, articles and books, the recent one being a book entitled International Water courses Law and A perspective of Nepal-India Cooperation. Presently, he is associated with JVS, a civil society organization for water resources development. He is also a member of Eminent Persons' Group (EPG).

E-mail: mail@jvs.org.np or suryanathupadhyay@ gmail.com 
Prakash Gaudel, joined Nepal Electricity Authority (NEA) in 2011. He is currently working as an Assistant ManageratEnvironmentandSocialStudies Department of NEA. He holds M.Sc. degree in Interdisciplinary Water Resources Management from Nepal Engineering College (Pokhara University) and M.Sc. in Environment Science from Kurukshetra University, India.

Corresponding E-mail: prakgaudel@gmail.com

\section{References}

Bhattarai, D. 2009. Multi-purpose Projects In: The Nepal-India Water Relationship- Challenges (eds. D.N. Dhungel and S.B. Pun), Springer, pp.69-98.

MoEn, 2016. National Energy Crisis Eradication Concept Paper and Electricity Development Decade 2072. Ministry of Energy, Government of Nepal, Kathmandu.

MoF, 2016. Economic Survey- Fiscal year 2016/17. Ministry of Finance, Government of Nepal, Kathmandu.

MoP-GoI, 2016. Guidelines on Cross Border Trade of Electricity. Ministry of Power, Government of India.

MOPE, 2004: Initial National Communication to the Conference of Parties of the United Nations Framework Convention on Climate Change. Ministry of Population and Environment, Government of Nepal, Kathmandu.

MoWR, 1985. Master Plan Study on the Kosi River water Resources Development, Final Report, Ministry of Water Resources and Japan International Cooperation Agency.

NPC, 2016. The Fourteenth Plan, National Planning Commission, Government of Nepal, Kathmandu.

Poudel, S.N. 2009. Water Resource UtilizationIrrigation. In: The Nepal-India Water RelationshipChallenges (eds. D.N. Dhungel and S.B. Pun), Springer, pp.99-124.

Pun, S.B, 2008a. Hydropower Development in NepalLessons from Past Models. In: Hydro Nepal-Journal of Water, Energy and Environment, Issue 2, Media for Energy Nepal, Kathmandu, pp. 5-8.

Pun, S.B. 2008b. Paraguay, Bhutan and Nepal: Landlocked but Hydropower Rich-Cases of the Lame Duck, Flying Goose and Sitting Duck! In: Hydro Nepal-Journal of Water, Energy and Environment, Issue 3, Media for Energy Nepal, Kathmandu, pp. 9-13.

Pun, S.B. 2013. World Bank's 2012 Ganges Strategic Basin Assessment- A View from Nepal. In: Hydro Nepal-Journal of Water, Energy and Environment, Issue 12, Media for Energy Nepal, Kathmandu, pp. 6-12.

Pun, S.B. 2016. Too Many Fancy Bottles! In Nepal's New Power Sector Institutions- Electricity Development Decade 2072. In: Hydro Nepal-Journal of Water, Energy and Environment, Issue 19, Media for Energy Nepal, Kathmandu, pp. 6-10

Pun, S.B. 2017. Reflections on India's Guidelines on Cross Border Trade of Electricity vis-à-vis Nepal's Electricity Development Decade 2016/026 and 2017/o18 Budget. In: Hydro Nepal, Issue 21, Media for Energy Nepal, Kathmandu, pp. 5-10.

SARI/EI, 2016. Impact of Cross-Border Electricity Trade on Bhutan (Country Series), Working Paper, South Asia Regional Initiative for Energy integration,

Thanju, J.P. and Canese, R. 2011. Lessons from Hydropower Rich Paraguay. In: Hydro NepalJournal of Water, Energy and Environment, Issue 9, Media for Energy Nepal, Kathmandu, pp. 7-11.

Upadhyay, S.N. 2012. International Water Courses Law and A Perspective on Nepal-India Cooperation. Ekta Books, Kathmandu, Nepal.

Upadhyay, S.N. and Gaudel, P. 2017. The Adoption of the Declaration of the Principles on the Grand Ethiopian Renaissance Dam and Lessons for South Asia. In: Hydro Nepal-Journal of Water, Energy and Environment, Issue No. 21 (July, 2017), Media for Energy Nepal, Kathmandu, pp.17-24.

Upadhyay, S.N. and Gaudel, P. 2014. Cross-border Downstream Benefit Sharing in Reservoir Type Hydropower Projects: Case of Budhi Gandaki Storage Project in Nepal. In: Hydro Nepal-Journal of Water, Energy and Environment, Issue No. 14 (January, 2014), Media for Energy Nepal, Kathmandu, pp.59-64.

WB, 2014. Ganges Strategic Basin Assessment - A Discussion of Regional Opportunities and Risks, World Bank South Asia Regional Report, Report No. 67668-SAS, World Bank.

WECS, 2017. Electricity Demand Forecast Report (2015-2040). Water and Energy Commission Secretariat, Government of Nepal, Kathmandu.

WECS, 2011. Water Resources of Nepal in the Context of Climate Change. Water and Energy Commission Secretariat, Government of Nepal, Kathmandu.

WECS, 2005. National Water Plan, Water and Energy Commission Secretariat, Government of Nepal, Kathmandu.

WECS, 2002. Water Resources Strategy Nepal. Water and Energy Commission Secretariat, Government of Nepal, Kathmandu.

\section{Footnotes}

1. These estimates are based on available data of certain stations up to the year 1995 .

2. About $78 \%$ of the average flow in Nepal is available in for major river basins of Koshi, Gandaki, Karnali and Mahakali, however only $42 \%$ of the population resides in these basins (WECS, 2002).

3. This ever-cited hydropower potential of Nepal of $83000 \mathrm{MW}$ is the finding of $\mathrm{PhD}$ thesis carried out by H.M. Shrestha in 1966. And even after five decades, the same figure is referred, Recent findings of WECS also match with this data.

4. As of June 25, 2018; according to Department of Electricity Development, 88 hydro-projects are in operation which have a total installed capacity of 1006.78 MW

5. South Asian Association for Regional Cooperation (SAARC), established in 1985, comprises of eightmember States of Afghanistan, Bangladesh, Bhutan, India, Maldives, Nepal, Pakistan and Sri Lanka.

6. This decade is foreseen to commissioning of 133 
hydro-projects totaling $9935 \mathrm{MW}$ of electricity. Out of this 117 RoR projects of 2,587 MW; 5 peakingRoR projects of $1975 \mathrm{MW}$ and 11 storage projects totaling $5373 \mathrm{MW}$ are envisaged to be completed by 2026 (MoEn, 2016).

7. Bhutan sells electricity as much cheaper price in the region. The electricity from the $336 \mathrm{MW}$ Chhukha HP is sold as the rate of Bhutanese Ngultrum (BTN) 2.25 per unit (revised from BTN 2 per unit from Jan. 2014); BTN 1.98 per unit (revised from BTN 1.75 per unit from Jan 2008) from 6o MW Kurichhu HEP and BTN 1.98 per unit from 1020 MW Tala HEP (SARI/EI, 2016).

8. The Guidelines entail one time approval from Designated Authority of India for eligible power trading entities and India will import electricity from projects outside India which are owned or funded by Indian Government/Public Sector Unit or by private companies with $51 \%$ or more Indian entity ownership.

9. The total installed capacity of electricity in India is 343,898 MW by 31.05.2018 out of which majority (64.8\%) comes from thermal projects and only
14.5\% from hydro-projects (Ministry of Power, Government of India)

10.The popularly sited examples are construction of Tanakpur and Farakka barrages. In case of Tanakpur, India started constructing the barrage across the Mahakali River, which forms the international boundary between two nations, unilaterally without informing Nepal.

11. NEA- an undertaking of Government of Nepal, was established in 1985 through the merger of Department of Electricity of MoWR, Nepal Electricity Corporation and related Development Boards. This merging was done in order to remedy the inherent weakness associated with these fragmented electricity organizations with overlapping and duplication of works.

12. DoED has issued generation license to Mountain Hydro Nepal for developing 21.6 MW Lower Hewa project in 2013 and to Kabeli Energy Limited for developing 37.6 MW Kabeli A project in 2012.

13. Though NEA has applied for survey license of 762 MW Tamor Project, the department has issued the license of $200 \mathrm{MW}$ only and asked NEA to downsize the project. However, the project is not feasible at 200 MW. 